\title{
Two Ways to Particularize a Property
}

Journal of the American Philosophical Association, 2015, 1(4), 635-652.

\author{
Robert K. Garcia \\ Texas AEM University \\ robertkgarcia@gmail.com \\ www.robertkgarcia.com
}

\section{Request from the author:}

If you would be so kind, please send me a quick email if ...

- you are reading this for a university or college course, or

- you are citing this in your own work.

It is rewarding to know how my work is being used, especially if it has been adopted as required or recommended reading.

Thank you.

\section{Citation Information:}

- Garcia, Robert K. (2015) "Two Ways to Particularize a Property" Journal of the American Philosophical Association, 2015, 1(4), 635-652. 


\section{Journal of the American Philosophical Association}

http://journals.cambridge.org/APA

Additional services for Journal of the American Philosophical Association:

Email alerts: Click here

Subscriptions: Click here

Commercial reprints: Click here

Terms of use : Click here

\section{Two Ways to Particularize a Property}

ROBERT K. GARCIA

Journal of the American Philosophical Association / Volume 1 / Issue 04 / December 2015, pp $635-652$

DOI: 10.1017/apa.2015.21, Published online: 29 December 2015

Link to this article: http://journals.cambridge.org/abstract S2053447715000214

How to cite this article:

ROBERT K. GARCIA (2015). Two Ways to Particularize a Property. Journal of the American Philosophical Association, 1, pp 635-652 doi:10.1017/apa.2015.21

Request Permissions : Click here 


\title{
Two Ways to Particularize a Property
}

\begin{abstract}
Trope theory is an increasingly prominent contender in contemporary debates about the existence and nature of properties. But it suffers from ambiguity concerning the nature of a trope. Disambiguation reveals two fundamentally different concepts of a trope: modifier tropes and module tropes. These types of tropes are unequally suited for metaphysical work. Modifier tropes have advantages concerning powers, relations, and fundamental determinables, whereas module tropes have advantages concerning perception, causation, character-grounding, and the ontology of substance. Thus, the choice between modifier tropes and module tropes is significant and divides the advantages of trope theory simpliciter. In addition, each resulting trope theory is unstable: modifier trope theory threatens to collapse into realism, and module trope theory threatens to collapse into austere nominalism. This invites reflection on the stability of trope theory in general.
\end{abstract}

KEYWORDS: tropes, universals, nominalism, ontology, substance

Questions concerning the existence and nature of properties remain the subject of vigorous and far-reaching debate. The most general disagreement concerns whether properties exist at all (for recent overviews, see Edwards 20I4 and Koons and Pickavance 20I5). Austere nominalists hold that, strictly speaking, there are no properties but only primitively charactered objects; there are spherical objectsbilliard balls and the like-but no sphericity (or sphericities) per se (for discussion, see Loux 2006 and Carroll and Markosian 2010). Other philosophers hold that properties exist in some sense or other but disagree on what properties are like-on the kind of entity that plays the role(s) of property (see Edwards 20I4; Koons and Pickavance 2015; Lewis I983; Oliver I996; and Swoyer I999). Among those

An ancestor of this paper is forthcoming in Spanish as "Sobre la expresión "propiedades particularizadas?": Tropos modificadores y tropos módulo', (translated by E. Zerbudis) in E. Zerbudis (ed.), Poderes Causales, Tropos, y Otras Criaturas Extrañas: Estudios de Metafísica Analítica (Buenos Aires: Título). For discussion I wish to thank audiences at the 20I4 meeting of the North Carolina Philosophical Society, University of North Carolina at Chapel Hill; the Programa de Pós-graduação Lógica e Metafísica, Universidade Federal de Rio de Janeiro, Brazil; the Instituto de Filosofía, Pontificia Universidad Católica de Chile, Santiago, Chile; the Tercer Coloquio de Metafísica Analítica, 2012, Buenos Aires, Argentina; the Segundo Congreso Latinoamericano de Filosofía Analítica, 201 2, Buenos Aires, Argentina; and the second annual Houston Baptist University Philosophy Conference, 20I2. For helpful comments I especially thank several anonymous referees as well as Anthony Adrian, José Tomás Alvarado, Dong An, Richard Cross, Tobias Flattery, John Forcey, Sophie Gibb, John Heil, Rob Koons, Michael Loux, E. J. Lowe, Alex Oliver, Timothy Pickavance, Gonzalo Rodriguez-Pereyra, Jeff Snapper, Peter van Inwagen, and Ezequiel Zerbudis. 
positing unconstructed, fundamental properties, an important dispute concerns whether properties are universals (see Armstrong I980a, I980b, I989, I997; Moreland 200I, 2013; and van Inwagen 2004) or tropes (see Campbell I990; Ehring 20I I; Maurin 2002; Molnar 2003; and Williams I953).

Realists posit universals, which are shareable, or 'repeatable' properties. A universal is shareable in that it can characterize several wholly distinct objects at once. For example, on realism, it is possible that two distinct spheres exist simultaneously, such that the sphericity of one is (numerically) identical with the sphericity of the other; the sphericity is a universal.

Trope theory is an increasingly prominent alternative to realism. In fact, the concept of a universal is often used as a foil for introducing the concept of a trope. This is captured in the recurring slogan that 'tropes are particularized properties'. As I show below, however, the slogan is ambiguous because 'particularizing' can be understood in at least two ways. These correspond to two concepts of a trope, to what I call modifier tropes and module tropes. The modifier/module distinction stems from a suggestion by Michael Loux (2OI 5: 3 I). I should note, however, that for reasons given in Garcia (20 I 5 a: I33-34), I use the term 'module trope' for what Loux calls a 'troper', and I use 'modifier trope' for what he simply calls a 'trope'.

The modifier/module distinction seems to track and illuminate what Anna-Sofia Maurin (2014) describes as a 'choice of model for the trope', between thinking of tropes as substances and thinking of tropes as properties. On her view, however, the choice is ultimately inconsequential: 'tropes are by their nature such that they can be adequately categorized both as a kind of property and as a kind of substance' (20I4, emphases in original). I will argue to the contrary. Rather than representing an inconsequential choice between two ways of modeling a single kind of trope, the modifier/module distinction represents a significant choice between two fundamentally different kinds of tropes.

The structure of the article is as follows. In the first section I distinguish the two concepts of a trope and situate the two resulting trope theories against rival views, such as realism and austere nominalism. In section 2 I argue that modifier tropes and module tropes are unequally suited for metaphysical work: modifier tropes have advantages concerning powers, relations, and fundamental determinables, whereas module tropes have advantages concerning perception, causation, charactergrounding, and the ontology of substance. This shows that the choice between modifier tropes and module tropes is significant and divides the advantages of trope theory simpliciter. In section 3 I argue that each resulting trope theory is unstable: modifier trope theory threatens to collapse into a version of realism, and module trope theory threatens to collapse into austere nominalism. This invites reflection on the stability of trope theory in general. In the concluding section, I briefly consider whether a trope theorist might gainfully employ both types of tropes.

\section{Modifier Tropes versus Module Tropes}

The first way to particularize a property is to take a universal and simply render it unshareable. Understood in this way, the slogan says that a trope is a nonshareable 
version of what is otherwise a universal. That is, unlike a universal, a trope cannot characterize multiple nonoverlapping objects at once. On a theory of universals, it is possible that two distinct particles $a$ and $b$ exist simultaneously, where the property whereby $a$ is negatively charged is (numerically) identical with the property whereby $b$ is negatively charged. Whereas on trope theory, if there are two charged particles, $a$ and $b$, then the property whereby $a$ is negatively charged is nonidentical with (though exactly similar to) the property whereby $b$ is negatively charged. Philosophers who gloss the slogan this way include Campbell (I990), Carroll and Markosian (2010), Ehring (I997), Lewis (200I), Martin and Heil (I999), Molnar (2003), and Oliver (I996).

These discussions do not specify whether the working concept is that of a selfexemplifying or non-self-exemplifying universal. Nevertheless, the context suggests that tropes are being compared to something like Armstrong's universals, which are generally non-self-exemplifying (his [I980a: 7If] discussion of the third-man problem suggests that he denies that, generally speaking, universals are selfexemplifying). If so, the slogan says that shareability exhausts the conceptual difference between tropes and non-self-exemplifying universals. Thus understood, the slogan fixes on the concept of a modifier trope: a nonshareable and nonself-exemplifying property. On a modifier trope theory, a billiard ball is hard in virtue of its hardness trope and spherical in virtue of its sphericity trope, but the hardness trope is not itself hard and the sphericity trope is not itself spherical. Thus, a modifier trope does not confer its own character to an object, but confers character that somehow is grounded in and produced by the character of the trope itself.

To elucidate the sense in which a modifier trope does not confer its own character to an object, it may be useful to compare a modifier trope to a truthmaker. Presumably, in some cases truthmaking is irreflexive, in that there is a truthmaker (verifier) that is not itself true but makes something else true. Similarly, a modifier trope is what we might call a character-maker (characterizer) in that it makes something else charactered but the trope is not itself charactered in that way. The latter caveat is necessary because it is misleading to say that a modifier trope isn't charactered at all. For example, although a sphericity modifier trope isn't spherical, it is charactered both formally (being a property, being self-identical, being nonshareable, etc.) and functionally (being a sphere-maker). Most trope theorists take the formal and functional character of a trope to be primitive and not grounded in (say) universals or higher-order tropes (for an exception see Ehring [20II], where a trope has its nature in virtue of belonging to primitively natural classes).

The concept of a modifier trope offers one way to understand the nature of a trope on a substance-attribute ontology, like that of C. B. Martin (I980) or E. J. Lowe (2006). Lowe, for example, has (in personal conversation) rejected module tropes and although his writing is not entirely unambiguous on the module/modifier distinction, on balance it seems reasonable to take his 'modes' to be modifier tropes.

There is a stronger sense of 'particularize' and so another way to understand the slogan-a way that fixes on the concept of a module trope. In a more robust sense, 'particular' means propertied thing or object. Understood in this 
sense, 'particularizing a property' involves ascribing objecthood to a property (and, perhaps by implication, unshareability as well). Unlike the weaker sense of particularization, this conceptual transformation seems to involve traversing categories-from property to object. In this stronger sense, particularization involves converting a shareable singly characterizing property (a universal) into a nonshareable minimally or singly propertied object (a module trope). The 'minimally or singly' is a hedge I address below. In the interim, I will simply use 'minimally'.

The concept of a module trope appears in several discussions. Armstrong (I989: I I 5), citing A. J. Ayer, mentions a trope concept on which tropes are minimally charactered 'junior substances'. Peter Forrest reiterates the idea:

As I understand it, tropes are not so much properties that familiar objects have as rather mini-substances that would ordinarily be thought of as having a location and one other property. (I993: 47)

James van Cleve makes a similar comment:

\begin{abstract}
When I read accounts of what 'particularized properties' are supposed to be, I cannot help thinking that they belong to the category of particulars rather than to the category of properties. A 'particular redness' seems really to be a special kind of red particular. (Perhaps it is a particular that exemplifies just one property, redness, and that one essentially.) (I985: IOI-O2)
\end{abstract}

These passages take a 'particularized property' to be a minimally propertied particular. Understood in this way, the slogan picks out the concept of a module trope.

It is important to note that the strong sense of 'particularize' should not be conflated with substantializing a property in the sense of making the property into an independent entity - that is, into a property that can exist independently of its (or any) bearer. Indeed, both independent modifier tropes (transferable or even free-floating modifier tropes) and dependent (nontransferable) module tropes are conceivable. Thus, it seems that there are two conceptual distinctions here: between dependent and independent tropes and between modifier and module tropes. Although it might be natural to take modifier tropes to be dependent and module tropes to be independent, it is not obvious that these pairings are necessary, and in what follows I will not assume that they are.

As the above quotations suggest, module tropes have similarities to bare particulars and to the ordinary objects of austere nominalism. To see this, suppose we have a spectrum representing the degree to which a theory's fundamental entities are primitively, intrinsically, and naturally (nonformally) charactered. At one end is the noncharactered bare particular; at the other end is the fully charactered ordinary object of the austere nominalist. The module trope sits somewhere on the theoretical turf between them. 
On the one hand, a module trope is similar to a bare particular in the following respect. Considered in itself, a bare particular is completely devoid of natural (nonformal) character. In contrast, aside from being minimally charactered, a module trope has no other natural character. It is, as it were, a barely-not-bare particular.

On the other hand, module trope theory and austere nominalism agree that there are primitively naturally charactered fundamental entities. They disagree over the thickness of primitive character. Austere nominalism takes fundamental entities to be primitively fully charactered. On this view, an electron is primitively chargedand-massive. In contrast, module trope theory takes fundamental entities to be primitively minimally charactered. On this view, a fully charactered ordinary object is fully charactered in virtue of having several primitively minimally charactered tropes. Here, an electron is supposed to be charged and massive in virtue of having two distinct tropes, where one is primitively massive and the other is primitively charged.

\section{Relative Merits}

I will now argue that modifier tropes and module tropes are unequally suited for metaphysical work. I'll do so by outlining several advantages of each theory over the other.

\section{I Merits of Modifier Tropes}

Modifier tropes enjoy an advantage in at least three areas, including powers, relations, and determinables.

First, modifier tropes are better suited than module tropes to be the powers (or dispositions) of objects. Anna Marmodoro introduces her volume on powers with the following gloss: 'Powers are properties like fragility and electric charge, whose possession disposes their bearer in a certain way. The instantiation of fragility in the glass disposes the glass to break if struck in the appropriate circumstances' (20I0: I, emphasis mine). This is a typical and natural way to talk about powers, and it suggests that generally powers are not self-disposing. Rather, the natural way to understand a power is to take a power to dispose its bearer. On this way of thinking, magnetism is not itself magnetic; rather, magnetism disposes its bearer to attract nearby ferrous metals. The general assumption that powers are not self-disposing seems especially evident in discussions of the identity criterion for powers and the status of so-called higher-level powers. For example, Lowe's identity criterion includes the clause that token powers are identical only if their bearers are identical (20IO: I2). This would be redundant if powers were self-disposing. With respect to higher-level powers, the idea is that something has (say) the power to roll down an inclined plane in virtue of having other (perhaps dispositional) properties including sphericity, rigidity, and heaviness. This would seem to require that each of the latter properties disposes something other than itself-a distinct bearer. The 
latter is jointly disposed by lower-level powers and thereby has the higher-level power to roll down a plane. Lower-level powers, then, would seem to be non-selfdisposing. But if powers are non-self-disposing, then if a power is a trope, it is a trope that does not have the character it grounds-that is, it is a modifier trope. Thus, modifier tropes are better suited than module tropes to be the powers of objects.

Second, modifier tropes are better suited than module tropes to play the role of relations. In disputes about the status of relations on a trope ontology, the operative concept is almost certainly that of a modifier trope. Here, it would seem that the concept of a relation module trope is a nonstarter. Indeed, this is because the very concept of a relation module trope looks incoherent. On a trope ontology, disputes about relations largely focus on the putative relations of resemblance and compresence and typically concern whether the postulation (reification) of resemblance or compresence tropes would generate a vicious regress. For example, although relation tropes are rejected by Campbell (I990), they are explicitly postulated by more recent trope theorists, such as Maurin (2002) and Ehring (20II). More importantly, Armstrong's (I997: I2-I3) 'ontological free lunch doctrine' is typically assumed in these discussions. Its bearing is this: if pairwise character supervenes on a pair of entities, then a genuine, reified, relation trope is not necessary to ground the pairwise character (Campbell I990: 37). In other words, there is a two-place relation trope $R$ only if the existence of the pair of $R$ 's terms is consistent with the nonexistence of $R$. Of course, if the existence of the pair of $R$ 's terms is consistent with the nonexistence of $R$, then the pair is not identical with $R$. Thus, a two-place relation trope is not identical with the pair it relates, and so either (I) a two-place relation trope is identical with a pair other than the pair whose pairwise character the trope grounds, or (2) a two-place relation trope is not identical with any pair. If $(\mathrm{I})$, then the relation trope is itself a pair and thus is at least the kind of entity that could have pairwise character. Unfortunately, however, such a trope could have the pairwise character it grounds (i.e., it could be a module relation trope) only by introducing a seemingly vicious regress: If the pairwise character of the original pair requires grounding, then so does the similar pairwise character of the pair that is the relation trope. So (I) is not a viable option. Thus, there is a two-place relation trope only if $(2)$ is the case. That is, the two-place relation trope is not identical with a pair. This means the relation trope cannot have pairwise character, and thus, the relation trope cannot have the character it grounds. In other words, a two-place relation trope cannot be a module trope. This argument generalizes to all many-place relations. If there are any such relations, they are not module tropes.

Third, modifier tropes are better suited than module tropes to play the role of fundamental determinables. A determinable is a less than fully specific property. Examples include mass, color, and shape. Associated with (or 'falling under') the latter determinables are fully determinate properties, such as mass I $\mathrm{kg}$, scarlet, and sphericity. A determinable property is fundamental if it is distinct from and irreducible to fully determinate properties (Wilson 20I 2: 5).

To see how modifier and module tropes fare differently, consider the determinable triangularity and suppose that triangularity $y_{\mathrm{I}}$ is a fundamental 
determinable trope. On module trope theory, triangularity I $_{\mathrm{I}}$ would itself be triangularly shaped, but not in any fully determinate way. It would be something with three sides and three angles, but none of the angles would have a specific degree and none of the sides would have a specific length. Thus, triangularity I $_{\mathrm{r}}$ would be a triangle but it would be neither equilateral, isosceles, nor scalene. Such an entity seems impossible. In contrast, on modifier trope theory, triangularity $_{\mathrm{I}}$ would not itself be triangularly shaped: it would be neither indeterminately triangularly shaped nor fully determinately triangularly shaped. There seems to be nothing impossible about such a modifier trope. It would ensure that its bearer is shaped in some triangular way or other, but it would not ensure that its bearer is (say) equilateral. Thus, in contrast to modifier trope theory, on module trope theory, postulating fundamental determinables seems to be a nonstarter.

Perhaps it is not surprising, then, that many trope theorists deny that determinables are fundamental and, instead, identify determinables with so-called property classes (for example, Campbell I990; Ehring I996, 20II; and Williams I953). On this view, a property class is a resemblance class of tropes, where membership in the class is defined in terms of degrees of resemblance. More precisely, a class $C$ of tropes is a property class if and only if (i) each member of $C$ resembles every other member of $C$ to some specific degree, and (ii) no trope that is not a member of $C$ resembles every member of $C$ to that degree (Manley 2002: 77). For example, the determinable property shape is said to be identical with the (loose) resemblance class that contains all and only fully determinate shape tropes: all sphericities, all cubicities, etc. Property classes have been employed to play various roles within trope theory (for details, see Oliver I996 and Manley 2002).

Although many trope theorists have eschewed fundamental determinables, there are reasons to doubt that an adequate trope theory can do without them. Indeed, there are several ways they might earn their keep. I will mention three.

To begin, fundamental determinable tropes might be needed to construct adequate property classes out of tropes. Building on Williams (I953), Campbell (I990) argues that property-classes of tropes can provide the semantic values for abstract terms while avoiding the occult universals of the realist and being immune to the well-known imperfect community and companionship problems raised by Nelson Goodman (I966) against object-class resemblance nominalism. This immunity thesis has been challenged by David Manley (2002), who argues that the project of constructing property-classes out of tropes runs into tropist versions of the imperfect community and companionship problems. Setting aside other issues (about which see Garcia 2015a), the important point is Manley's observation that a trope theorist might avoid both of the Goodman-style objections by postulating fundamental determinable tropes (2002: 88). To be sure, this move is not unproblematic. Manley notes several worries, including concerns about parsimony, persistence conditions, and causation. These worries cannot be assessed here, but recent work goes some distance toward addressing them, especially the work of Wilson (2OI2), to which we turn next. At the very least, the verdict is out on whether and to what extent these concerns are ultimately problematic. 
Jessica Wilson (2OI2) has argued that fundamental determinables are needed to ground certain modal facts about determinables. To illustrate, suppose we have spherical piece of clay. The piece has the determinable being shaped but that determinable might have been otherwise determined-it might have been (say) cubically determined rather than spherically determined. Thus, there are modal facts about determinables, and according to Wilson, fundamental determinables are needed to account for those facts.

Finally, Ingvar Johansson has argued that fundamental determinables are needed 'to explain the basic scales of mathematical physics' (20I4: 239). To illustrate the scales that Johansson has in mind, consider the fact that any pair of length tropes are more similar than any length trope and any mass trope. For example, a io $\mathrm{m}$ length trope differs less from a $10^{100} \mathrm{~m}$ length trope than from a $\mathrm{IO} \mathrm{kg}$ mass trope (20I4: 238). In this sense, there is an 'ontological gap' between different kinds of tropes. Johansson argues that trope theory requires fundamental determinables to explain these gaps.

To sum up, unlike the modifier trope theorist, the module trope theorist does not have the option of postulating fundamental determinables. But, all things being equal, a theory of tropes on which fundamental determinables are possible is better than one on which they are not. Moreover, arguably, there is important work for fundamental determinable tropes to do. Thus, it is an advantage of modifier trope theory that it allows for fundamental determinables.

\subsection{Merits of Module Tropes}

Module tropes, however, have their own advantages. These concern perception, causation, character-grounding, and the ontology of substance.

The first two are related. According to many trope theorists, an important advantage of tropes over universals is that tropes are uniquely suited to be the immediate objects of perception and the terms of causal relations (Campbell I98I; Ehring 1997; Lowe 2006; Schaffer 200I; and Williams 1953). Unfortunately, modifier tropes do not enjoy these advantages.

First, contrary to how tropes are often advertised, modifier tropes seem ineligible to play a direct role in perception. According to Lowe, '[W] hen I see the leaf change in colour-perhaps as it is turned brown by a flame-I seem to see something cease to exist in the location of the leaf, namely, its greenness. But it could not be the universal greenness which ceases to exist, at least so long as other green things continue to exist.' (I998: 205) I will put the underlying argument here as follows:

Suppose we have two green leaves, Leaf $_{\mathrm{I}}$ and Leaf ${ }_{2}$. As Leaf $\mathrm{I}_{\mathrm{I}}$ is subjected to a flame, we see its greenness cease to exist. Leaf ${ }_{2}$ is not subjected to heat, and we see its greenness continue to exist. Thus, when we saw Leaf $_{I}$ 's greenness, what we directly perceived was neither the greenness of Leaf $_{2}$, nor greenness in general (a universal). Rather, we directly perceived the particular greenness of $\operatorname{Leaf}_{\mathrm{I}}$ (a trope). 
When generalized, this sort of argument suggests that, unlike universals, tropes are especially well-suited to play a direct role in perception: to be the basic percepts.

Unfortunately, this sort of argument does not fare well on modifier trope theory. Let $p$ stand for whatever it is that I directly perceive when I perceive the greenness

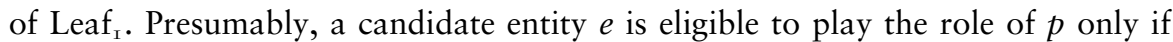

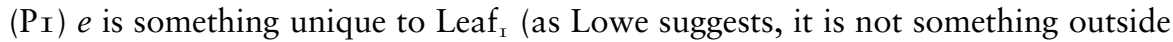
the location of Leaf ${ }_{\mathrm{I}}$ ) and $\left(\mathrm{P}_{2}\right) p$ is itself (greenly) colored.

As I will discuss below, trope theorists have argued that an important advantage of tropes is that tropes, unlike universals, satisfy $\left(\mathrm{PI}_{\mathrm{I}}\right)$ in virtue of being nonshareable. Indeed, the nonshareability of tropes ensures that $\left(\mathrm{PI}_{\mathrm{I}}\right)$ is satisfied on both module and modifier trope theory: on each view, the greenness of Leaf does not characterize anything other than Leaf $_{\mathrm{I}}$ and is nonidentical with the greenness of Leaf $f_{2}$. However, it is not the case that $\left(\mathrm{P}_{2}\right)$ is satisfied on both theories: a greenness trope is itself colored only on module trope theory. Thus, despite its nonshareability, a modifier trope is not the kind of entity one can immediately perceive, much less the sort of entity one can directly perceive to cease to exist in the location of a leaf. As such, a greenness modifier trope is not eligible to play the role of $p$, the immediate percept in the leaf case. But greenness modifier tropes are not unique in this regard. On the modifier view, a sweetness trope is not sweet, a temperature trope is not (say) hot, a smoothness trope is not smooth, and so on. Thus, unlike module tropes, modifier tropes seem ineligible to play a direct role in perception.

Second, for similar reasons, modifier tropes seem ineligible to play a direct role in causation. Again, this is contrary to the usual billing. Consider Maurin's remarks:

According to a majority of the trope theorists, tropes have an important role to play in causation. It is, after all, not the whole stove that burns you, it is its temperature that does the damage. And it is not any temperature, nor temperature in general, which leaves a red mark. That mark is left by the particular temperature had by this particular stove now or, in other words, it is left by the stove's temperature-trope. (20I4, emphases in original)

When generalized, this sort of argument suggests that, unlike universals, tropes are especially well-suited to play a direct role in causation: to be the basic causal relata.

For reasons that are parallel to those concerning the perception case, this sort of argument does not fare well on modifier trope theory. To see why, call the stove in Maurin's example Stove ${ }_{1}$ and suppose there is another, Stove ${ }_{2}$, that is exactly alike with respect to temperature. Each is, say, 500 degrees Fahrenheit. Let $c$ stand for whatever it is that is directly causally responsible for the burn mark on my hand. Presumably, a candidate entity $e$ is eligible to play the role of $c$ only if $\left(\mathrm{C}_{\mathrm{I}}\right.$ )

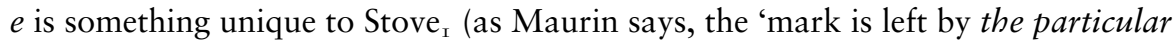
temperature had by this particular stove now') and $\left(\mathrm{C}_{2}\right) e$ is itself hot.

Trope theorists have argued that an important advantage of tropes is that tropes, unlike universals, satisfy $\left(\mathrm{C}_{\mathrm{I}}\right)$ in virtue of being nonshareable. Indeed, $(\mathrm{CI})$ is satisfied on both module and modifier trope theory: on each view, 
the hotness of Stove $_{\mathrm{I}}$ does not characterize anything other than Stove $_{\mathrm{I}}$ and is nonidentical with the hotness of Stove $_{2}$. However, it is not the case that (C2) is satisfied on both theories: a hotness trope is itself hot only on module trope theory. Thus, despite its nonshareability, a modifier hotness trope is not eligible to play the role of $c$, the immediate cause of the burn mark. But hotness modifier tropes are not unique in this regard. On the modifier view, mass tropes are not massive, charge tropes are not charged, and so on. Thus, unlike module tropes, modifier tropes seem ineligible to play a direct role in causation.

Third, with respect to character-grounding, module tropes are less mysterious than modifier tropes. Put simply, unlike module tropes, modifier tropes give what they don't have. A sphericity modifier trope is not itself spherical, yet somehow makes it the case that its bearer is spherical; here, there is something in the result of character-grounding that does not exist in the character-grounder itself. Indeed, the result of character-grounding bears no qualitative resemblance to the charactergrounder itself. In contrast, on the module view, character-grounding need not involve the mysterious production of novel character. For example, a sphericity module trope is able to ground the sphericity of its bearer precisely because the trope is itself spherical. Indeed, a module trope theorist might even say that the bearer's being spherical amounts to nothing more than the bearer's having a proper part (a trope) that is spherical (a strategy I discuss in Garcia, forthcoming). Thus, unlike modifier tropes, module tropes go some distance toward dispelling 'the ancient mystery of predication' (Williams I953: I I).

Fourth, module tropes are better suited than modifier tropes for a bundle theory of substance (for more on this issue, see Garcia 20I $5 \mathrm{a}$ and forthcoming). Trope theorists are divided over bundle theory. Several reject it, including Heil (2OI2), LaBossiere (I994), Lowe (2006), and Martin (I980). According to many, however, taking properties to be tropes, rather than universals, makes it possible to do without substrata and to maintain that objects are bundles of all and only properties (Campbell I990; Ehring 20I I; Maurin 2002; and Schaffer 200I). The idea is that, unlike tropes, shareable properties cannot differentiate qualitatively indiscernible objects, and thus, taking properties to be universals requires an additional category of differentiating entities: substrata or bare particulars (for more on bare particulars see Garcia 2OI 4 and Pickavance 20I4; for the subtle differences between substrata and bare particulars see Gracia I988: 87). Thus, tropes are said to have the advantage over universals of allowing for a parsimonious mono-category ontology and avoiding mysterious and paradoxical substrata (Schaffer 200I: 248).

Unfortunately, it is doubtful that modifier tropes can do without substrata. Even if substrata are not needed on either version of trope theory to differentiate substances, there is other work for substrata to do for which modifier tropes are not suited. Suppose sphericity I $_{\mathrm{I}}$ is a sphericity trope. In its role as a charactergrounder, sphericity s $_{\mathrm{I}}$ s supposed to account for the fact that something is spherical. Call the latter something a 'trope-bearer'. On module trope theory, because sphericity $_{\mathrm{I}}$ is itself spherical, there is at least the theoretical option of identifying the trope-bearer with sphericity ( $_{\mathrm{I}}$ see Garcia, forthcoming). On modifier trope 
theory, however, sphericity I $_{\mathrm{I}}$ is not itself spherical, and thus the entity which is spherical (in virtue of the trope) must be something numerically distinct from sphericity $_{\mathrm{I}}$. In other words, on modifier trope theory, a trope-bearer is a distinct entity that is characterized by a trope. If sphericity s $_{\mathrm{I}}$ a modifier trope, then it spherizes its bearer. It seems, then, that modifier trope theory requires a category of trope-bearers in addition to a category of tropes-not to differentiate substances, but to be the literal subjects of characterization-to be the entities that are charactered in virtue of having tropes. This, however, is one of the traditional roles played by substrata. Differentiating substances is not the only role they are supposed to play. Thus, unlike module tropes, modifier tropes seem to rule out the much lauded advantages that come with a mono-category ontology that avoids substrata. (See Garcia 20 I 5 a and forthcoming for more on these issues and for a discussion of how the choice between modifier and module tropes bears on the choice between bundle and substance-attribute theories of substance.)

In this section I have argued that modifier tropes have advantages concerning powers, relations, and determinables, whereas module tropes have advantages concerning perception, causation, character-grounding, and the ontology of substance. In this way, modifier tropes and module tropes are unequally suited for metaphysical work. This is not to say, however, that they are equally unsuited for metaphysical work-that the choice between them is a wash. Although I take each of the disadvantages of each type of trope to be significant, I do not undertake here the difficult task of determining the relative weights of those disadvantages.

\section{Theoretical Instabilities}

I have argued that there are several ways in which modifier tropes and module tropes are unequally suited for metaphysical work. Drawing from several of these inequalities, in the remainder I will argue that each trope concept is unstable: modifier trope theory threatens to collapse into realism, and module trope theory threatens to collapse into austere nominalism.

\section{I Modifier Trope Theory and Realism}

Perhaps the most fundamental disagreement between trope theorists and realists concerns shareability. Indeed, it is fair to say that the ideological hallmark of trope theory is the judgment that taking properties to be nonshareable secures several important advantages over realism, advantages that outweigh whatever costs may be incurred by nonshareability (such as curtailing parsimony and explanatory power). Thus, if it turns out that the nonshareability of tropes is neither necessary nor sufficient to secure those advantages, then much of the rationale for trope theory is lost. In this section I will argue that this is how things turn out. That is, that on modifier trope theory, nonshareability is neither necessary nor sufficient to secure the important advantages that tropes are supposed to enjoy over universals. The advantages I have in mind are the four standard rationales for trope theory, as noted by Jonathan Schaffer (200I: 247-48). I will discuss each in turn. 
The first advantage that nonshareability is supposed to secure is that of safeguarding the intuitively plausible principle that no entity is wholly located at two or more nonoverlapping places at once. Following Reinhardt Grossmann (I992: I3), I will call the latter principle the Axiom of Location (AOL).

Preserving AOL is routinely advertised as one of trope theory's important virtues and advantages over immanent realism. On the latter view, defended most prominently by D. M. Armstrong (I980b, I989, I997), universals 'are as fully present in space and time as their bearers' (O'Leary-Hawthorne and Cover I998: 205). Immanent realism faces the long-standing objection that its shareable properties violate AOL. One way to put the objection is as follows. Suppose I am holding two billiard balls, one in each hand. According to realism, sphericity is literally shared by the two balls. That is, the sphericity of the ball in my right hand is identical with the sphericity of the ball in my left hand. Thus, because sphericity is shared by the balls, it is wholly located at two nonoverlapping locations at once, thus violating AOL. Worse, because sphericity is wholly located in both hands, it somehow moves away from itself as I spread my arms. In this way, shareability is said to saddle realism with significant, perhaps prohibitive, implausibility and counterintuitiveness.

Trope theory is said to enjoy the advantage of avoiding this scandalous and counterintuitive result by denying that properties are shareable (Campbell I98I: 477). In this way, the preservation of AOL provides a rationale for the nonshareability of tropes and secures an advantage for trope theory not enjoyed by immanent realism.

But shareability by itself does not violate AOL. Rather, the violation results from the conjunction of shareability and the principle that a property characterizes a located object only if the property is wholly located where that object is located. Call the latter principle '(L)'. Given (L), a property that can characterize several remote objects at once can thereby be wholly located at multiple nonoverlapping places at once. But without (L), shareability does not violate AOL. In light of points made above, however, it seems that on modifier trope theory there is little to no motivation for (L). In fact, modifier trope theory seems incompatible with (L).

Above I argued that a modifier trope is intrinsically charactered only formally (being a property, being self-identical, being nonshareable, etc.) and functionally (e.g., being a sphere-maker). For example, not only is a sphericity modifier trope not spherical, presumably it is not shaped at all-it is not, say, cubical-and, a fortiori, it is not sized, massive, charged, temperatured, and so on. I also argued that a modifier trope is neither immediately perceivable (a greenness trope is not colored so you cannot directly perceive it) nor the sort of entity that could play a direct causal role (a hotness trope is not temperatured so it cannot be the immediate cause of a burn). These considerations make it difficult to see how a modifier trope could be spatiotemporally located. After all, how could an entity be spatially located if it is incapable of being the direct cause of anything and is neither shaped, nor sized, nor massive, nor temperatured, and so on-that is, if it is entirely devoid of natural character? But if a modifier trope cannot be located, then modifier trope theory is incompatible with (L). 
If $(\mathrm{L})$ is false, then a property can simultaneously characterize several distinct objects without being wholly located in multiple places at once. In other words, if $(\mathrm{L})$ is false, then AOL is consistent with shareability. Thus, the falsity of (L) would be sufficient to preserve AOL, regardless of whether or not properties are shareable. But if AOL is preserved independently of the nonshareability of properties, then preserving AOL fails to provide a rationale for nonshareability. Thus, given that $(\mathrm{L})$ is false on modifier trope theory, AOL is preserved independently of the nonshareability of modifier tropes. Thus, preserving AOL fails to provide a rationale for the nonshareability of modifier tropes.

To sum up, in itself, a modifier trope is neither an immediate percept nor a direct cause, and it is, moreover, devoid of natural character, being only formally and functionally charactered. Minimally, this suggests that there is nothing about a modifier trope that requires it to be spatiotemporal. Arguably, it suggests that modifier tropes are non-spatiotemporal. Either way, it suggests that modifier trope theory is compatible with the falsity of $(\mathrm{L})$. But the falsity of $(\mathrm{L})$ would suffice to safeguard AOL. Thus, although modifier trope theory enjoys the advantage over immanent realism of safeguarding AOL, nonshareability does not play a role in securing this advantage. Thus, the preservation of AOL fails to provide a rationale for the nonshareability of modifier tropes.

The second advantage that nonshareability is supposed to secure concerns perception. As previously, many trope theorists hold that an important advantage of tropes over universals is that tropes are uniquely suited to be the immediate objects of perception.

Unfortunately, modifier tropes do not enjoy this advantage. This was illustrated above, where I noted two necessary conditions-( $\left.\mathrm{PI}_{\mathrm{I}}\right)$ and $\left(\mathrm{P}_{2}\right)$ - for being whatever it is that I directly perceive when I perceive the greenness of Leaf ${ }_{\mathrm{I}}$. Unlike a greenness universal, both modifier tropes and module tropes satisfy $\left(\mathrm{PI}_{\mathrm{I}}\right)$ in virtue of being nonshareable. As before, however, although a greenness modifier trope is nonshareable, it does not satisfy $\left(\mathrm{P}_{2}\right)$. More generally, the nonshareability of modifier tropes is not sufficient to make them immediately perceivable. Unlike module tropes, modifier tropes do not enjoy the advantage over universals of being eligible to be the immediate objects of perception. Thus, securing this advantage fails to provide a rationale for the nonshareability of modifier tropes.

The third advantage nonshareability is supposed to secure concerns causation. In virtue of being nonshareable, tropes, unlike universals, are supposed to be uniquely suited to be the basic terms of causal relations.

For reasons akin to those concerning perception, modifier tropes do not enjoy this advantage. This was illustrated in the case concerning the hotness of Stove $_{\mathrm{I}}$, where I noted two necessary conditions-(CI) and ( $\left.\mathrm{C}_{2}\right)$ - for being whatever it is that is directly causally responsible for the burn mark on my hand. Unlike a hotness universal, both modifier tropes and module tropes satisfy $\left(\mathrm{CI}_{\mathrm{I}}\right)$ in virtue of being nonshareable. Again, however, although a hotness modifier trope is nonshareable, it does not satisfy $\left(\mathrm{C}_{2}\right)$. More generally, the nonshareability of modifier tropes is not sufficient to make them eligible to be direct causes. Unlike module tropes, modifier tropes do not enjoy the advantage over universals of being eligible to be the basic 
terms of causation. Thus, securing this advantage fails to provide a rationale for the nonshareability of modifier tropes.

The fourth advantage nonshareability is supposed to secure concerns the ontology of substance. As previously, many trope theorists hold that taking properties to be nonshareable allows for a bundle theory-a parsimonious monocategory ontology that avoids mysterious and paradoxical substrata (Schaffer 200I: 248). As argued above, however, modifier trope theory requires a category of trope-bearers in addition to tropes-not to differentiate substances, but to provide the entities that are characterized by modifier tropes. In being subjects of characterization, trope-bearers play one of the traditional roles assigned to substrata. Thus, because modifier tropes require distinct trope bearers, the nonshareability of modifier tropes is not sufficient to secure the advantage over universals of making bundle theory viable. Thus, securing this advantage fails to provide a rationale for the nonshareability of modifier tropes.

I have considered four important advantages that nonshareability is supposed to secure for tropes over universals. Perhaps there are other advantages that nonshareability might secure, but the above four comprise a large and important part of the standard rationale for taking properties to be tropes rather than universals. I have argued, however, that the nonshareability of modifier tropes is not necessary for the first advantage and not sufficient for the second, third, and fourth advantages. Thus, on modifier trope theory, principled motivations for the nonshareability of tropes are in short supply. In this way and in this sense, modifier trope theory threatens to collapse into realism.

\subsection{Module Trope Theory and Austere Nominalism}

It is time to reconsider the recurring hedge that module tropes are 'minimally' charactered. This hedge marks a latent ambivalence concerning the exact degree to which a module trope is primitively charactered. More importantly, it harbors a theoretical instability.

Sometimes tropes are described in a way that suggests that they are only singly charactered-witness the above remarks by van Cleve and Forrest as well as Campbell (I976: 2I6, fn I2 and I98I: 485). More often, however, trope theorists describe tropes in a way that suggests that tropes are multiply charactered. As Armstrong notes, trope theorists 'tend to give [tropes] spatial and temporal characteristics: shape, size, and duration. In this way the trope is swelled up a bit' (I 989: I I 5). The idea that tropes are (or can be) primitively multiply charactered is clearly the working assumption of some trope theorists, such as Campbell (I990) and Robb (2005). It is also tacitly assumed by prominent critics of trope theory, such as Moreland (1989, I997, 200I) and Manley (2002). To be sure, however, the tendency to thicken the primitive character of module tropes is a principled one. After all, it is difficult to see how anything could be (say) spherical without also being charactered in other ways, such as being sized. Manley, for example, takes it for granted that the shape trope of a square would itself not only have to be square, but would have to have perpendicular sides and an interior right angle (2002: 85 ). 
Unfortunately, however principled it may be, this thickening tendency threatens to collapse module trope theory into austere nominalism. Both views ultimately deploy the same general strategy: postulate primitively multiply charactered entities. That is, they agree that one need not give an analysis of multiply charactered objects. But the module trope theorist takes a further, speculative step: she takes the character of fully charactered objects to demand an analysis and meets this demand by taking fully charactered objects to have a theoretically novel metaphysical structure consisting in less-than-fully, yet multiply charactered tropes. However, if the character of multiply charactered objects can be primitive, then why not dispense with postulating a structure and simply take the character of fully charactered objects to be primitive? Absent an answer to this question, it is not clear how module trope theory is either different from or better than austere nominalism.

A module trope theorist might respond by following Schaffer $(2003)$ in resisting the thickening tendency. Schaffer argues for the metaphysical possibility of a mass trope that is massive but not otherwise charactered. Such a (module) trope would be a primitively singly charactered object. However, to forestall the collapse into austere nominalism, the module trope theorist must upgrade Schaffer's thesis in two significant ways. First, its scope must be extended to include all possible types of tropes. And second, it must be strengthened from affirming the possibility of singly charactered tropes to affirming the impossibility of multiply charactered tropes. Whether these upgrades are plausible and motivated merits reflection. I have my doubts.

\section{Going Forward}

Trope theory is a leading alternative to realism and austere nominalism. But it suffers from an ambiguity concerning the nature of a trope. Disambiguation reveals a distinction between modifier tropes and module tropes. These types of tropes are unequally suited for metaphysical work. Modifier tropes have advantages concerning powers, relations, and fundamental determinables, whereas module tropes have advantages concerning perception, causation, character-grounding, and the ontology of substance. Thus, the choice between modifier tropes and module tropes is significant and divides the advantages of trope theory simpliciter. In addition, each resulting trope theory is unstable: modifier trope theory threatens to collapse into realism, and module trope theory threatens to collapse into austere nominalism. This invites reflection on the stability of trope theory in general. (To this end, in 'Tropes as Divine Acts' (2015b), I argue that a modifier trope theory may be improved by taking modifier tropes to be identical with certain divine acts.)

Going forward, it is natural to ask whether a trope theorist might gainfully employ both types of tropes. Such an approach-call it the 'hybrid view'-is discussed by Koons and Pickavance (2015: I22) and is tacitly equated with trope theory by others. According to G. S. Rosenkrantz, for example, some tropes are modifier tropes and some are module tropes. On his understanding of trope theory, a wisdom trope is a modifier trope: 'A trope such as Aristotle's wisdom would not, of course, itself be wise: it is Aristotle who is wise' (I993: 5 , fn 7). But a squareness 
trope is a module trope: 'it appears that the particular squareness of a certain object is square, and hence possesses spatial parts' (r 993: 5, fn 7). Nevertheless, although it is not entirely unheard of, the hybrid view marks a relatively uncharted region of theoretical space, and it is not clear whether the view has ever been seriously defended. Thus, I think it would be more judicious to invite further exploration of the view rather than to risk a precipitous verdict. That said, I'd like to conclude by offering a few general remarks about the hybrid view and by briefly considering a possible instance of it.

It seems doubtful that the hybrid view would mitigate the foregoing concerns about each type of trope. Consider, for example, the most natural way to develop the hybrid view: take module tropes to be characterized by modifier tropes. With respect to the theoretical instability problems, it is not clear that this move would stabilize either type of trope. On the one hand, the nonshareability of modifier tropes would be no more motivated than it was before. Thus, the hybrid view adds nothing to modifier tropes that would forestall their collapse into universals. On the other hand, it is less clear whether the hybrid view could forestall the collapse of a module trope into an object on par with the primitively multiply charactered object of the austere nominalist. As previously, to prevent this collapse, the hybrid view must deny that a module trope is multiply primitively charactered. It cannot be, say, primitively spherical-and-sized. And, on pain of converting the module trope into a bare particular, the view must affirm that a module trope has some primitive natural character-that is, the trope must be primitively naturally charactered in at least one way. It must be at least, say, primitively spherical. Thus, the hybrid view forestalls the collapse into austere nominalism only if it takes every module trope to be, in itself, only singly primitively charactered. By my lights, this marks a significant condition for the viability of the hybrid view.

It may be that the trope bundle theory developed by David Robb is a hybrid view. According to Robb, the principle of unity for bundles at the lowest mereological level is identity: 'For any substantially simple object $O$ and properties $F$ and $G$ : $F$ and $G$ are qualitative parts of $O$ iff $F$ and $G$ are each identical with $O$ ' (2005:486). Here, the tropes of simple objects are identical with their bearers. Thus, if (say) a mass trope is identical with its bearer, then the trope is itself massive. It is, in other words, a module trope. More generally, on Robb's view, it seems that the tropes had by (and thus identical with) simple substances are module tropes. Robb also allows that at higher mereological levels there are tropes that are structured (ultimately) on simple substances (where the latter, I take it, are module tropes). Thus, Robb's view is a hybrid view if higher level tropes characterize their base(s) in the way that a modifier trope characterizes its bearer. However, it is not clear if this is how the view is supposed to work. Where $t$ is a higher level trope, it is not clear whether $t$ 's being structured on simple substance $O$ involves $t$ 's existentially depending on $\mathrm{O}$ or also t's characterizing $\mathrm{O}$ (in the way that a modifier trope would). So it is not clear whether Robb's is a hybrid view. Regardless, however, his module tropes (simple substances) are threatened with the instability described above. His view is predicated on the assumption that (at least some) simple substances have multiple tropes. Without this assumption, there would be no motivation for the strategy of 
unifying the simple substance (qua bundle) via identity. Thus, where $O$ is a simple substance that is identical with multiple module tropes, $O$ is primitively multiply charactered. For example, if simple object $O$ has a charge trope and a mass trope, then $O$ is identical with those tropes, and thus, $O$ is primitively charged-andmassive. In this way, Robb's simple substances (module tropes) are on a par with the multiply primitively charactered objects of the austere nominalist. Hence, the threat of collapse remains unmitigated.

ROBERT K. GARCIA

TEXAS A\&M UNIVERSITY

robertkgarcia@gmail.com

\section{References}

Armstrong, D. (1980a) Nominalism and Realism: Universals and Scientific Realism. Vol. I. New York: Cambridge University Press.

Armstrong, D. (I980b) Universals and Scientific Realism: A Theory of Universals. Vol 2. New York: Cambridge University Press.

Armstrong, D. (1989) Universals: An Opinionated Introduction. Boulder, CO: Westview Press.

Armstrong, D. (1997) A World of States of Affairs. New York: Cambridge University Press.

Campbell, K. (1976) Metaphysics: An Introduction. Encino, CA: Dickenson.

Campbell, K. (I990) Abstract Particulars. Oxford: Basil Blackwell.

Campbell, K. (1981) 'The Metaphysic of Abstract Particulars'. Midwest Studies in Philosophy, 6, $477-88$.

Carroll, J., and N. Markosian. (20I0) An Introduction to Metaphysics. New York: Cambridge University Press.

Edwards, D. (20I4) Properties. Cambridge, UK: Polity.

Ehring, D. (I996) 'Mental Causation, Determinables and Property Instances'. Nous, 30, 46 I-80.

Ehring, D. (I997) Causation and Persistence: A Theory of Causation. New York: Oxford University Press.

Ehring, D. (20II) Tropes: Properties, Objects, and Mental Causation. New York: Oxford University Press.

Forrest, P. (I993) 'Just like Quarks'. In J. Bacon, K. Campbell, and L. Reinhardt (eds.), Ontology, Causality, and Mind: Essays in Honor of D. M. Armstrong (New York: Cambridge University Press), $45^{-65}$.

Garcia, R. K. (20I4) 'Bare Particulars and Constituent Ontology'. Acta Analytica, 29, I49-59.

Garcia, R. K. (2015a) 'Is Trope Theory a Divided House?' In G. Galluzzo and M. Loux (eds.), The Problem of Universals in Contemporary Philosophy (New York: Cambridge University Press), I33-55.

Garcia, R. K. (2015b) 'Tropes as Divine Acts: The Nature of Creaturely Properties in a World Sustained by God'. European Journal for Philosophy of Religion, 7, I05-I30.

Garcia, R. K. (Forthcoming) 'Tropes as Character-Grounders'. Australasian Journal of Philosophy.

Goodman, N. (1966) The Structure of Appearance. Indianapolis, IN: Bobbs-Merrill.

Gracia, J. J. E. (1988) Individuality: An Essay on the Foundations of Metaphysics. Albany, NY: SUNY Press.

Grossmann, R. (1992) The Existence of the World: An Introduction to Ontology. New York: Routledge.

Heil, J. (2OI2) The Universe as We Find It. New York: Oxford University Press.

Johansson, I. (2014) 'All Relations are Internal: The New Version'. In A. Reboul (ed.), Mind, Values, and Metaphysics: Philosophical Essays in Honor of Kevin Mulligan (New York: Springer), 225-40 
Koons, R. C., and T. H. Pickavance. (2015) Metaphysics: The Fundamentals. West Sussex, UK: Wiley-Blackwell.

LaBossiere, M. (1994) 'Substances and Substrata'. Australasian Journal of Philosophy, 72, 360-70.

Lewis, D. (I983) 'New Work for a Theory of Universals'. Australasian Journal of Philosophy, 6I, $343-77$.

Lewis, D. (200I) On the Plurality of Worlds. West Sussex, UK: Wiley-Blackwell.

Loux, M. J. (2006) Metaphysics: A Contemporary Introduction. Hoboken, NJ: Taylor \& Francis.

Loux, M. J. (2015) 'An Exercise in Constituent Ontology'. In G. Galluzzo and M. Loux (eds.), The Problem of Universals in Contemporary Philosophy (New York: Cambridge University Press), 9-45.

Lowe, E. J. (1998) The Possibility of Metaphysics. Oxford: Clarendon Press.

Lowe, E. J. (2006) The Four-Category Ontology: A Metaphysical Foundation for Natural Science. New York: Oxford University Press.

Lowe, E. J. (2010) 'On the Individuation of Powers'. In A. Marmodoro (ed.), The Metaphysics of Powers: Their Grounding and their Manifestations (New York: Routledge), 8-26.

Manley, D. (2002) 'Properties and Resemblance Classes'. Nô̂s, 36, 75-96.

Marmodoro, A. (2010) The Metaphysics of Powers: Their Grounding and their Manifestations. New York: Routledge.

Martin, C. (1980) 'Substance Substantiated'. Australasian Journal of Philosophy, 58, 3-10.

Martin, C., and J. Heil. ( 1999) 'The Ontological Turn'. Midwest Studies in Philosophy, 23, 34-60.

Maurin, A.-S. (2002) If Tropes. Dordrecht: Kluwer Academic Publishers.

Maurin, A.-S. (20I4) 'Tropes'. In E. N. Zalta (ed.), The Stanford Encyclopedia of Philosophy (Fall 2014 ed.). Available at: http://plato.stanford.edu/archives/fall2or $4 /$ entries/tropes/.

Molnar, G. (2003) Powers: A Study in Metaphysics. New York: Oxford University Press.

Moreland, J. P. (I989) 'Keith Campbell and the Trope View of Predication'. Australasian Journal of Philosophy, 67, 379-93.

Moreland, J. P. (I997) 'A Critique of Campbell's Refurbished Nominalism'. The Southern Journal of Philosophy, 35, 225-46.

Moreland, J. P. (200I) Universals. Montreal: McGill Queens University Press.

Moreland, J. P. (2013) 'Exemplification and Constituent Realism: A Clarification and Modest Defense'. Axiomathes, 23, 247-59.

O'Leary-Hawthorne, J., and J. A. Cover. (I998) 'A World of Universals'. Philosophical Studies, 9I, 205-I9.

Oliver, A. (1996) 'The Metaphysics of Properties'. Mind, I05, I-80.

Pickavance, T. (20I4) 'Bare Particulars and Exemplification'. American Philosophical Quarterly, 5 I, 95-I08.

Robb, D. (2005) 'Qualitative Unity and the Bundle Theory'. The Monist, 88, 466-92.

Rosenkrantz, G. S. (1993) Haecceity: An Ontological Essay. Dordrecht: Springer Science \& Business Media.

Schaffer, J. (200I) 'The Individuation of Tropes'. Australasian Journal of Philosophy, 79, 247-57.

Schaffer, J. (2003) 'The Problem of Free Mass: Must Properties Cluster?' Philosophy and Phenomenological Research, 66, I25-38.

Swoyer, C. (1999) 'How Ontology Might be Possible: Explanation and Inference in Metaphysics'. In P. A. French and H. K. Wettstein (eds.), Midwest Studies in Philosophy, vol. 23 (Minneapolis, MN: University of Minnesota Press), Io0-3 I.

van Cleve, J. (I985).'Three Versions of the Bundle Theory'. Philosophical Studies, 47, 95-107.

van Inwagen, P. (2004) 'A Theory of Properties'. In D. Zimmerman (ed.), Oxford Studies in Metaphysics, vol. I (New York: Oxford University Press), 107-38.

Williams, D. C. (I953) 'On the Elements of Being: I'. The Review of Metaphysics, 7, 3-18.

Wilson, J. M. (20I2) 'Fundamental Determinables'. Philosophers' Imprint, I2, I-I7. 